\title{
A comparison of the efficacy of gastric lavage, ipecacuanha and activated charcoal in the emergency management of paracetamol overdose
}

T. J. UNDERHILL*, M. K. GREENE ${ }^{\dagger} \&$ A. F. DOVE ${ }^{\dagger}$

* Accident and Emergency Department, University Hospital Nottingham and

${ }^{+}$Department of Accident and Emergency Medicine, Derbyshire Royal Infirmary, Derby

\section{SUMMARY}

The aim of this prospective trial was to compare the efficacy of gastric lavage activated charcoal and ipecacuanha at limiting the absorption of paracetamol im overdose and to assess the significance of the continued absorption of paracetamot following treatment. Patients aged 16 and over who had ingested 5 gms or more oo paracetamol within $4 \mathrm{~h}$ of admission were entered into the trial. The percentag $\overrightarrow{8}$ fall in plasma paracetamol level was used as the measure of the success of . treatment at limiting absorption. The mean percentage fall was 39.3 for gas lavage, 52.2 for activated charcoal and 40.7 for ipecacuanha, with a significan difference between the treatment methods $(p=0.03)$. Activated charcoal was more

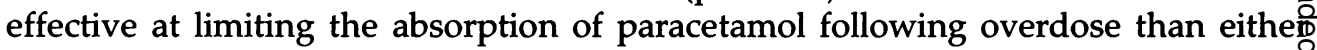
gastric lavage or ipecacuanha induced emesis. In treated patients continuing paracetamol absorption is not significant if more than $2 \mathrm{~h}$ have elapsed since ingestion.

\section{INTRODUCTION}

Paracetamol taken alone or in combination is now the drug most frequently used in deliberate overdose in Nottingham (Table 1). The management of these patients in the emergency department involves treatment to minimize the absorption of the drug by gastric lavage, ipecacuanha induced emesis or activated charcoalo Paracetamol is rapidly absorbed from the stomach and small bowel and procedures designed to reduce absorption are only worthwhile if carried out within $4 \mathrm{~h}$ of ingestion (Prescott, 1983). It is recommended that plasma levels are measured $4 \mathrm{~h}$

Correspondence: T. J. Underhill, Accident and Emergency Department, Queens Medical Centre, Universitu Hospital, Nottingham NG7 2UH, U.K. 
Table 1. Principal drug taken in overdose in Nottingham, 1.5 .88 to 30.11.88. Total 843 overdoses.

\begin{tabular}{lr}
\hline Paracetamol & $43 \%$ \\
Benzodiazepines & $16 \%$ \\
Antidepressants & $8 \%$ \\
Salicylate & $7 \%$ \\
NSAID & $6 \%$ \\
Major tranquillizers & $3 \%$ \\
Antiepileptics & $3 \%$ \\
Codeine derivatives & $3 \%$ \\
Mefenamic acid & $2 \%$ \\
Others & $9 \%$ \\
Total & $100 \%$ \\
\hline
\end{tabular}

after ingestion and definitive treatment is then commenced if indicated. It is thought that plasma levels taken before $4 \mathrm{~h}$ may not reflect the true extent of the overdose because of the possibility of continuing absorption (Prescott, 1983).

Controversy remains as to which of the three methods used to prevent drug absorption is the most effective. The aim of this prospective trial was to compare the three methods by monitoring the plasma paracetamol levels in the clinical situation. Previous studies in humans have investigated the recovery of drugs following gastric emptying procedures or the absorption of drugs in volunteers.

\section{SUBJECTS AND METHODS}

The trial was run concurrently in the Accident and Emergency Departments of the Derbyshire Royal Infirmary and the University Hospital, Nottingham, between April and October 1988. Ethical committee approval was obtained at both hospitals and the inclusion of a group who did not receive absorption limiting treatment was also approved at Derby.

Patients aged 16 and over who had ingested 5 or more grams of paracetamol within $4 \mathrm{~h}$ of attendance were entered into the trial. Patients were randomly allocated into one of four treatment groups: (1) Gastric Lavage (36 FG tube); (2) Activated Charcoal (Carbomix to drug ratio of 10:1); (3) Ipecacuanha Syrup $30 \mathrm{mls}$. (repeated after $30 \mathrm{~min}$ if no response); and (4) No Treatment to limit absorption (Derby only). Any patient with a depressed concious level or with a condition such as previous gastric surgery that might preclude the use of any one of the treatment methods was excluded from the trial.

Plasma paracetamol levels were measured on samples taken from an indwelling cannula prior to any treatment, and following treatment at 60,90 and 150 minutes after the first sample. The sample which corresponded most closely to the 4 hourly specimen was sent for urgent analysis. In no patient did treatment with intravenous acetylcysteine overlap with the trial period.

Additional information documented on arrival included the patient's estimate of 
the amount of paracetamol ingested and the time of ingestion, whether alcohol or $\frac{\vec{\Phi}}{0}$ other drugs had also been taken and whether the patient had vomited before 3 arriving at the department. Following treatment the amount of charcoal swallowed $\stackrel{\circ}{\circ}$ by the patient and the time taken for the emetic to act were also recorded, as were $\vec{\Rightarrow}$ any complications of the procedures.

The percentage change between the first and last plasma levels was used as a measure of the effectiveness of the different procedures at limiting absorption. The intermediate levels served to confirm the trend and to record the time of the maximum plasma level. Statistical evaluation of the results was by Analysis of Variance using the SPSS-X statistical package (Prescott, 1983).

\section{RESULTS}

Sixty patients were included in the study, 44 women and 16 men. The age range was 16 to 62 years with a mean of 25.7. The age and sex distribution was similar $\vec{\infty}$ for each treatment group. Forty-eight patients took paracetamol alone and the 9 additional drugs taken by the remainder are listed in Table 2 . Twenty-one patients $\overrightarrow{0}$ reported consuming alcohol with the tablets and seven had vomited prior to $\frac{\pi}{0}$ arriving at the Department. Patients presented to the department between 30 and $240 \mathrm{~min}$ after ingestion with a mean delay of $123 \mathrm{~min}$.

The mean paracetamol levels versus the mean times post ingestion for each treatment group are shown in Figure 1. There was a steep rise in the paracetam 8 levels in the group who did not receive any absorption limiting treatment wheñ compared to the three treatment groups, but this group did present earlier. If similar graph is plotted for patients presenting within $120 \mathrm{~min}$ of ingestion (Figure 2) it can be seen that the difference is due to the effect of treatment rather than the time of presentation.

Group 4 (no treatment group, Derby) was stopped for ethical reasons when the serum paracetamol levels increased between the first and last samples in four out of five patients. The paracetamol levels for those patients in groups 1, 2 and 3 fell (except patient No. 59, vide infra). The mean percentage fall between the first and

Table 2. Additional drugs taken with paracetamol.

\begin{tabular}{lr}
\hline Drugs ingested with paracetamol & \\
\hline No additional drug & 48 \\
Dextropropoxyphene & 4 \\
Codeine Phosphate & 1 \\
Aspirin & 2 \\
Diazepam & 2 \\
Caffeine & 1 \\
Quinine Sulphate & 1 \\
Ferrous Sulphate & 1 \\
Total & 60 \\
\hline
\end{tabular}




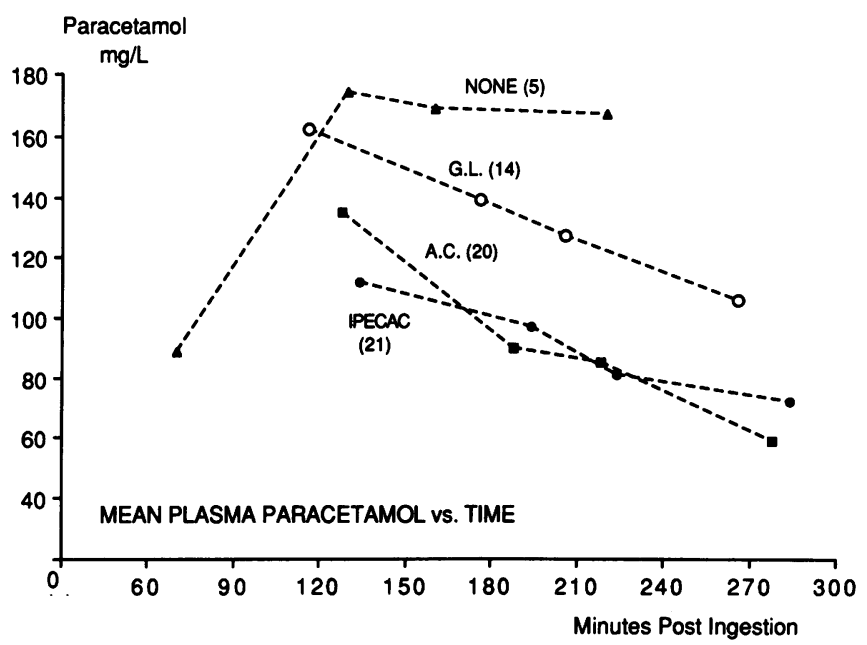

Fig. 1. Mean plasma paracetamol levels versus mean times following ingestion for all patients according to treatment group. G.L.-gastric lavage, A.C.-activated charcoal, None-no absorption limiting treatment.

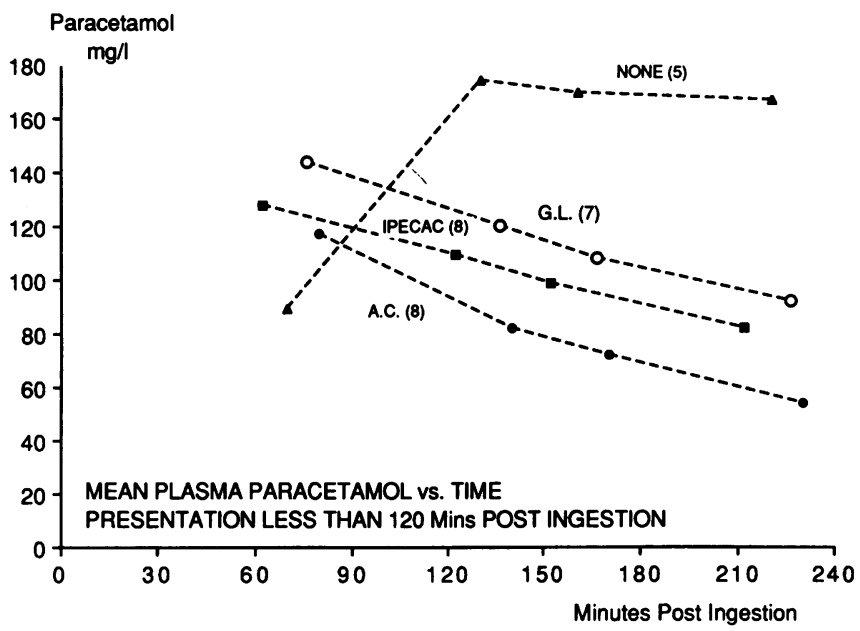

Fig. 2. Mean plasma paracetamol levels versus mean times following ingestion according to treatment group for patients presenting within $120 \mathrm{~min}$ of ingestion.

last plasma paracetamol levels was 39.3 for gastric lavage, 52.2 for activated charcoal and 40.7 for ipecacuanha (Table 3). Activated charcoal was more effective in lowering plasma paracetamol levels than either gastric lavage $(p=0.013)$ or ipecacuanha $(p=0.027)$. The difference between gastric lavage and ipecacuanha was not significant $(p=0.81)$.

The plasma levels for patients in groups 1, 2 and 3 were greatest on admission 
Table 3. Comparison of treatment methods.

\begin{tabular}{|c|c|c|c|}
\hline Group & no. & mean $\%$ fall & St. deviation \\
\hline (1) Gastric Lavage & 14 & 39.33 & $14 \cdot 67$ \\
\hline (2) Activated Charcoal & 20 & $52 \cdot 25$ & $13 \cdot 55$ \\
\hline (3) Ipecacuanha & 21 & $40 \cdot 70$ & $18 \cdot 26$ \\
\hline
\end{tabular}

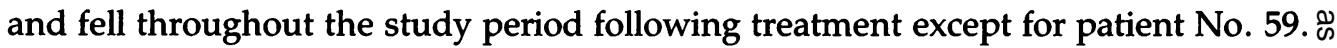
In this case the level rose to a maximum at $60 \mathrm{~min}$ after being seen, $(110 \mathrm{~min}$ after $\vec{\circ}$ ingestion), and was still $20 \%$ higher than the initial value at $150 \mathrm{~min}$. The patient $\overrightarrow{-}$ presented $50 \mathrm{~min}$ after ingesting 15 grams of paracetamol and vomited 15 min ${ }_{\odot}^{\omega}$ after treatment with ipecacuanha. All those patients who presented and were $\frac{\mathbb{\Phi}}{3}$ treated within $2 \mathrm{~h}$ of ingestion had maximal plasma levels at or before $2 \mathrm{~h}$ after ingestion. Patients presenting between 2 and $4 \mathrm{~h}$ after ingestion had maximal $\omega$ plasma levels at the time of presentation providing that they received absorption $\vec{\infty}$ limiting treatment.

The time to emesis in those patients given ipecacuanha ranged from 5 to $50 \mathrm{~min}=$ with a mean of $20 \mathrm{~min}$. Of the 20 patients given activated charcoal, 16 managed to $\frac{\mathscr{D}}{D}$ swallow the recommended amount (10 times the amount of drug ingested), two $\underset{\oplus}{\stackrel{\circ}{\oplus}}$ consumed half the recommended amount, one patient refused to swallow more $\bar{\sigma}$ than 20 grams and the amount of charcoal taken by one patient was not recorded.

Of the 21 patients treated with ipecacuanha two did not vomit until $50 \mathrm{~min}$ aftê $\vec{\otimes}$ treatment despite a repeat dose of emetic and a further two patients did not vom at all. Complications of activated charcoal included vomiting (4 patients, 3 of whom received 100 grams or more of charcoal) and 1 patient refused to swallow more than one mouthful. There were no complications related to gastric lavage in this series.

The ingestion of alcohol at the time of overdose did not significantly alter the $\overrightarrow{\vec{P}}$ efficacy of either gastric lavage $(p=0.106)$ or ipecacuanha $(p=0.323)$. For activated 3 charcoal, however, the mean fall in paracetamol level was reduced from $56 \%$ to $43 \%$ if alcohol was consumed $(p=0.049)$. Twelve patients ingested additional drugs but the numbers were too small for any conclusions to be draw. These 12 patients were spread throughout the three treatment groups and the results are similar when these patients are excluded from statistical analysis.

\section{DISCUSSION}

The early management of paracetamol poisoning is said to be well established: Patients presenting within $4 \mathrm{~h}$ of ingestion should undergo gastric lavage and the plasma concentration of paracetamol should be measured $4 \mathrm{~h}$ or more after overdose (Prescott, 1983; Meredith et al., 1986). The threshold at which treatment ${ }^{c}$ should be given is between $5 \mathrm{gms}$ (Prescott, 1983; Edinburgh Poisons Information Service, 1988) and $10 \mathrm{gms}$ (Meredith et al., 1986).

There is now a considerable amount of evidence to suggest that not only are $\stackrel{\mathbb{N}}{+}$ 
gastric emptying methods relatively inefficient but that activated charcoal is more effective at limiting drug absorption than either gastric lavage or ipecacuanha. The results of this trial in overdose patients confirm that activated charcoal is significantly more effective than either of the other two methods at reducing the absorption of paracetamol and suggest that providing patients receive treatment promptly plasma levels do not rise if more than $2 \mathrm{~h}$ have elapsed since ingestion.

Previous studies may be divided into those that measured the amount of drug recovered following gastric lavage or emesis in overdose patients and trials in volunteers that measured the amount of drug absorbed following absorption limiting procedures. In early trials looking at the recovery of drugs, usually barbiturates, from gastric washings the amount of drug recovered was low and in a significant proportion of patients no drug was recovered at all (Harstad et al., 1942, Allan, 1961; Matthew et al., 1966). Better results have been reported with other drugs with amounts equivalent to 10 therapeutic doses recovered in $50 \%$ of patients ingesting salicylate (Matthew et al., 1966) and 33\% of patients ingesting amitriptyline (Comstock et al., 1981). When gastric lavage is compared to emesis by measuring the recovery of administered markers it appears that lavage is more effective (Auerbach et al., 1986, Tanberg et al., 1986).

Three trials have compared activated charcoal with either gastric lavage or emesis by measuring the amount of ingested drug absorbed by volunteers (Curtis et al., 1984; Neuvonen et al., 1983; Tenenbein et al., 1987). All three trials showed activated charcoal to be significantly more effective at limiting drug absorption than either gastric lavage or emesis. In one of the studies an emetic given 30 min after ingestion of $1 \mathrm{gm}$ of paracetamol had no significant effect on absorption (Neuvonen et al., 1983).

In a study relating the early management of acutely poisoned patients to clinical outcome (Kulig et al., 1985) the addition of a gastric emptying procedure to treatment with activated charcoal conferred no benefit over treatment with activated charcoal alone.

Complications following gastric lavage include rupture of the oesophagus, aspiration pneumonia, laryngeal injury, arrythmias and cardiac arrest. In healthy patients lavage causes a rise in heart rate and a fall in arterial p02. The incidence of complications is approximately 3\% (Matthew et al., 1966). Lavage takes approximately $30 \mathrm{~min}$ to perform and requires at least two members of staff. The disadvantages of ipecacuanha induced emesis are the time before vomiting occurs and the variability in response between patients. The average time to emesis in this study was $20 \mathrm{~min}$ and is similar to that quoted by other authors (Curtis et al., 1984, Neuvonen et al., 1983, Tenenbein et al., 1987). Two patients had a delay of 50 minutes and a further two patients did not vomit at all. Complications of emesis include aspiration pneumonia, protracted vomiting and Mallory-Weiss tears (Vale et al., 1986).

Activated charcoal is tasteless but slighty gritty and in general is well tolerated by patients. It is recommended that the amount of charcoal given should be 10 times the amount of drug ingested but in practice giving more than $100 \mathrm{gms}$ of charcoal increases the risk of vomiting, as occurred in three of the seven patients in this trial who swallowed 100 gms or more. The optimum ratio, however, is not 
known and in vitro the maximum absorptive capacity is about $250 \mathrm{mg}$ paracetamol per gram of activated charcoal (Bainbridge et al., 1977). The absorptive capacity of charcoal is less in vivo and a charcoal to paracetamol ratio of 5 to 1 will reduce absorption by about $60 \%$ (Dordoni et al., 1973). Patients who have ingested up to $20 \mathrm{gms}$ of paracetamol can be conveniently treated with activated charcoal but clinicians may decide that a gastric emptying procedure is more practical for the larger overdose.

\section{ACKNOWLEDGEMENTS}

We would like to thank members of the medical and nursing staff at Derbyshire Royal Infirmary and University Hospital Nottingham for their help with this study.

\section{REFERENCES}

Allan B. C. (1961) The role of gastric lavage in the treatment of patients suffering from acute barbiturate overdose. Medical Journal of Australia 2, 513-4.

Auerbach P. S., Osterloh J., Braun O., Hu P., Geehr E. C., Kizer K. W. \& McKinney H. (1986) Efficacy of gastric emptying: gastric lavage versus emesis induced with ipecac. Annals of Emergency Medicine 15, 692-8.

Bainbridge C. A., Kelly E. L. \& Walking W. D. (1977) In vitro absorption of acetaminophen onte activated charcoal. Journal of Pharmaceutical Sciences 4, 480-3.

Comstock E. G., Faulkner T. P., Boisaubin E. V. \& Olson D. (1981) Studies on the efficacy of gastric lavage as practised in a large metropolitan hospital. Clinical Toxicology 18, 581-97.

Curtis R. A., Barone J. \& Giacona N. (1984) Efficacy of ipecac and activated charcoal/cathartic. Archives of Internal Medicine 144, 48-52.

Dordoni P., Willson R. A., Thompson R. P. H. \& Williams R. (1973) Reduction of absorption of paracetamol by activated charcoal and cholestyramine. British Medical Journal 3, 86-7.

Edinburgh Poisons Information Service (1988).

Harstad E., Moller K. O. \& Simesen M. H. (1942) Uber den Wert der Mangenspulung Behandlung von akuten Vergitfungen. Acta Medica Scandinavica 112, 478-514.

Kulig K., Bar-Or D., Cantrill S. V., Rosen P. \& Rumack B. H. (1985) Management of acutely poisoned patients without gastric emptying. Annals of Emergency Medicine 14, 562-7.

Matthew H., Mackintosh T. F., Tompsett A. L. \& Cameron J. C. (1986) Gastric aspiration and lavage in acute poisoning. British Medical Journal 1, 1333-7.

Meredith T. J., Prescott L. F., Vale J. A., Why do patients still die from paracetamol poisoning? British Medical Journal 293, 345-6.

Neuvonen P. J., Vartianen M., Tokola O., Comparison of activated charcoal and ipecac syrup in prevention of drug absorption. European Journal of Clinician Pharmacology 24, 557-62.

Prescott L. F. (1983) Paracetamol overdosage: Pharmacological considerations and clinical management. Drugs 25, 290-314.

SPSS-X User's guide (1983), McGraw Hill.

Tanberg D., Diven B. G. \& MeLeod J. W. (1986) Ipecac induced emesis versus gastric lavage: a controlled study in normal adults. American Journal of Emergency Medicine 4(3), 205-9.

Tenenbein M., Cohen S., Sitar D. S. (1987) Efficacy of ipecac induced emesis, orogastric lavage and activated charcoal for acute drug overdose. Annals of Emergency Medicine 16, 838-41.

Vale J. A., Meredith T. J. \& Proudfoot A. T. (1986) Syrup of ipecacuanha: is it really useful? British Medical Journal 293, 1321-2. 